\title{
Preparing future teachers to anticipate student difficulties in physics in a graduate-level course in physics, pedagogy, and education research
}

\author{
John R. Thompson, ${ }^{1}$ Warren M. Christensen, ${ }^{2}$ and Michael C. Wittmann ${ }^{1}$ \\ ${ }^{1}$ Department of Physics and Astronomy and Maine Center for Research in STEM Education, University of Maine, Orono, Maine, USA \\ ${ }^{2}$ Department of Physics, North Dakota State University, Fargo, North Dakota, USA \\ (Received 10 November 2009; revised manuscript received 4 February 2011; published 20 May 2011)
}

\begin{abstract}
We describe courses designed to help future teachers reflect on and discuss both physics content and student knowledge thereof. We use three kinds of activities: reading and discussing the literature, experiencing research-based curricular materials, and learning to use the basic research methods of physics education research. We present a general overview of the two courses we have designed as well as a framework for assessing student performance on physics content knowledge and one aspect of pedagogical content knowledge — knowledge of student ideas - about one particular content area: electric circuits. We find that the quality of future teachers' responses, especially on questions dealing with knowledge of student ideas, can be successfully categorized and may be higher for those with a nonphysics background than those with a physics background.
\end{abstract}

DOI: 10.1103/PhysRevSTPER.7.010108

PACS numbers: 01.40.J-

\section{INTRODUCTION}

With the growth of physics education research (PER) as a research field $[1,2]$ and the ongoing desire to improve teaching of introductory physics courses using reformbased approaches [3], there has been an opportunity to move beyond an apprenticeship model of learning about PER toward a course-driven structure. At the University of Maine, as part of our Master of Science in Teaching (MST) program, we have developed and are teaching two courses in Integrated Approaches in Physics Education [4]. These courses are designed to teach physics content, develop PER methods, and present results of investigations into student learning. The goal of our courses is to build a researchbased foundation for future teachers at the high school and university level as they move into teaching.

Teachers must satisfy many, many goals in their instruction. In part, teachers must be able to understand from where their students are coming, intellectually, as they discuss the physics. Teachers need to know how their students think about the content. Such an agenda has a long history in PER [5] and is one part of pedagogical content knowledge (PCK) [6]. We want to help teachers recognize how investigations into student learning and understanding have led to what is known about student thinking in physics, and how the results of this research inform curricular materials development. In order to do this, we expose (future) teachers to, and let them participate in, the research on student learning; from this, they can learn to properly analyze instructional

Published by the American Physical Society under the terms of the Creative Commons Attribution 3.0 License. Further distribution of this work must maintain attribution to the author $(s)$ and the published article's title, journal citation, and DOI. materials created based on research. And, to be consistent in our philosophy, we must attend to the future teachers' learning - of both physics content and pedagogy — as much as we wish for them to attend to students' learning. The activities described in this paper take part within a larger cycle of research, instruction, and evaluation, much as has been carried out in the PER community as a whole when developing instructional strategies to affect student learning.

In this paper, we propose to accomplish three tasks; the first two set the stage for the third. Before we describe our research, we first describe the two courses, the context in which they take place, and the activities that make up a typical learning cycle within the courses (elaborating on one such instructional unit from the course sequence in some detail). Second, we describe how we determine whether the future teachers have gained appropriate knowledge of student understanding and the role of different curricula. Finally, we draw from several semesters of data on future teacher learning of physics, pedagogy, and PER, looking at one topic that has been taught three times during this period. We present a framework for analyzing data on learning of physics content knowledge and of one aspect of pedagogical content knowledge-specifically, what conceptual difficulties a teacher might encounter among his or her students when teaching particular content. We then apply this framework to a small data set in order to provide a concrete example. All three of the tasks we have for this section are summarized in a single overarching research question: In a course designed to teach both content and pedagogy, how is future teacher knowledge affected by focused instruction with research-based materials and research literature documentation? In this paper, we present a method of assessment that we feel can be successfully used to address this question. 


\section{PEDAGOGICAL CONTENT KNOWLEDGE AND KNOWLEDGE OF STUDENT IDEAS}

Much of the literature on PER in the U.S.A. over the past 30 years deals with identification of student difficulties with specific physics concepts, models, relationships, or representations [7]. Past results of PER on student learning at the university level have led to the development of curricular materials designed to address common incorrect or naive student ideas using various pedagogical strategies [8-16]. These curricular innovations have helped improve student learning of physics concepts, as measured by performance on specific diagnostic assessments and/or surveys. In light of the history of PER, we believe that we must prepare future physics teachers to have an awareness of how their students might think about various topics, as well as an awareness of the kinds of curricular materials available to help guide students to the proper scientific community consensus thinking about the physics. This attention to student ideas in the classroom is one component of what Shulman labeled as "pedagogical content knowledge" [6]. Shulman describes PCK as "the particular form of content knowledge that embodies the aspects of content most germane to its teachability"; this includes knowledge of representations, analogies, etc. that make the content comprehensible, and "an understanding of what makes the learning of specific topics easy or difficult." The component of the description most relevant to our work, however, is "the conceptions and preconceptions that students of different ages and backgrounds bring with them to the learning of those most frequently taught topics and lessons." In teaching in a field such as physics, the use of analogies and representations are often helpful, if not essential, in developing a coherent and sensible understanding by students $[17,18]$. The ways in which students misunderstand, misinterpret, or incorrectly apply prior knowledge to common pedagogical tools need to be recognized by teachers who will be using these tools to teach and want to teach effectively.

In the larger science education research literature, research on science teachers' PCK has focused on the nature and the development of PCK in general, rather than investigating science teachers' PCK about specific topics in a discipline. van Driel and colleagues noted this issue in an article a decade ago [19]. In the context of results on a PCK-oriented workshop, the authors describe their own interpretation of and framework for PCK. The authors argue that PCK consists of two key elements: knowledge of instructional strategies incorporating representations of subject matter and understanding of specific learning difficulties and student conceptions with respect to that subject matter. They state that "the value of PCK lies essentially in its relation with specific topics." Our work speaks directly to this recommendation and emphasizes the second of their two key elements. van Driel et al. also suggest, based on their work and the literature review, what features a discipline-based PCK-oriented course should contain, including exposure to curricular materials and the study of what they refer to as "authentic student responses." Through specific assignments and discussions, participants may be stimulated to integrate these activities and to reflect on both academic subject matter and on classroom practice. In this way, participants' PCK may be improved.

In addition, van Driel et al. lament the contemporary state of research into teachers' PCK and make recommendations for a research agenda on teachers' PCK. From their review of the literature, they call for more studies on science teachers' PCK with respect to specific topics. Despite the apparent specificity of this approach, they argue that the results would benefit teacher preparation and professional development programs and classroom practice beyond any individual topic. As an example of such work, Loughran and colleagues [20] have conducted longitudinal studies of teachers in the classroom, and used the results to develop a different two-piece framework for PCK, involving content representations and teaching practice. We seek to advance this agenda in physics.

Magnusson et al. [21] present an alternate framework and discussion. They conceptualize PCK as pulling in and transforming knowledge from other domains, including subject matter, pedagogy, and context. They argue that this enables PCK to represent a unique domain of teacher knowledge rather than a combination of existing domains. They state that " ... the transformation of general knowledge into pedagogical content knowledge is not a straightforward matter of having knowledge; it is also an intentional act in which teachers choose to reconstruct their understanding to fit a situation. Thus, the content of a teacher's pedagogical content knowledge may reflect a selection of knowledge from the base domains" ([21], p. 111).

Magnusson et al. break down PCK for science teaching further than van Driel et al., into five components. Their first component is "orientations toward science teaching and learning," dealing with views about the goals of science teaching and learning, and how that perspective guides the teacher's instructional decisions. In PER one might classify this domain as the metacognitive and epistemological aspects of physics education. For example, Magnusson et al. describe the didactic orientation, whose goal is to "transmit the facts of science"; the accompanying instructional approach would be lecture or discussion, and questions to students would be used for the purposes of accountability for the facts. The importance of the orientation component is that it acts as the lens through which any teacher-or teacher educator, as they point out—views other aspects of PCK, especially curricular materials, instructional strategies, and assessment methods. Magnusson et al.'s main argument here is that a teacher's orientation 
influences, and may even determine, his or her pedagogical choices and perspectives. In PER one would present this argument in terms of a teacher's epistemological framing of their science instruction [22], where epistemological framing describes one's (in this case the instructor's) expectations for what it means to teach science and how their students learn science, and how these expectations influence their behavior within the classroom.

The other four components deal with knowledge and beliefs about science curriculum; students' understanding of specific science topics; science assessment, including methods and referents against which to assess; and sciencespecific instructional strategies. Most directly relevant to our work here is the student understanding category. This is further broken down into two parts. The first deals with requirements for student learning, which includes prerequisite knowledge as well as developmental appropriateness of particular representations. "Developmental appropriateness" refers to the degree to which students of varying abilities can successfully work with representations that require higher-order reasoning (e.g., three-dimensional models of atoms). The second component of understanding concerns areas of student difficulty, which includes difficulties with the abstract or unfamiliar nature of the concepts, with needed problem-solving skills, or with alternate (prior) conceptions (or specific difficulties) held by students. Magnusson et al. argue that knowledge of these student ideas, as we are referring to them, will help teachers interpret students' actions and responses in the classroom and on assessments. From their research and the literature they cite, they find that even teachers who know about student difficulties may lack knowledge about how to address these difficulties.

In the domain of mathematics, Ball and colleagues have developed a framework for what they have labeled "mathematics knowledge for teaching" [23,24]. They envision a set of knowledge split between subject matter knowledge (broken down further into common and specialized knowledge) and pedagogical content knowledge. PCK contains three subgroups of knowledge and content: those of teaching, students, and curriculum. This framework has only recently been established but is quite similar to the one we have used implicitly. In particular, we have focused on the knowledge of student ideas (KSI), described by Ball and collaborators as the knowledge of ideas about the content that students have been documented to have.

Within the PER community, Etkina discussed the building of physics-specific PCK-described as "an application of general, subject-independent knowledge of how people learn to the learning of physics" - as a central goal in building an ideal physics teacher preparation program [25,26]. Etkina emphasizes the domain specificity of PCK, underscoring the need for each discipline to have content-tailored PCK learned in teacher preparation programs. She points out that learning about PCK should be conducted in the same manner as effective content learning, via active learning, or in this case, active teaching. In [26], Etkina describes an entire graduate program for high school physics teacher preparation that embodies the principles of learning PCK, and in which students learn about many aspects of PCK and put them into practice. Etkina's necessary and careful work is consistent with the agenda of building a large-scale framework for PCK as described above. The lack of available PCK literature in PER is reflected by its absence in Etkina's references, and indicates the need for explicit attention within this community.

Knowledge of student ideas about specific concepts and representations is common to all of the definitions of PCK employed by the researchers cited above. The course goal that we focus on in this paper is to improve future teacher KSI in physics. We have chosen to concentrate on assessing this aspect of PCK that everyone agrees on as a necessary feature. By investigating future teacher ideas about student ideas about physics, and through teacher preparation curriculum development informed by previous education research, we are attempting to improve future teachers' understanding of this aspect of the learning and teaching of physics. Our work is not aimed at building a complete, large-scale framework for PCK in physics, although hopefully our results could be useful in helping inform researchers who wish to do so.

The need to include KSI and the results of PER in teacher preparation courses is justified by the analogy to the past use of PER to inform curriculum development in physics courses. Many PER studies have challenged the assumptions that physics instructors held about their students' understanding of basic physics concepts, representations, and reasoning. There has been a long history of the rich interplay of research, instruction, and evaluation. Early versions of research-based curricular materials were implemented by physics education researchers or the curriculum authors themselves running pilot studies at their home institutions. Similarly, there is great value in having research on KSI in physics take place in an instructional setting that is designed to help physics teachers develop KSI. Trained physics education researchers who are familiar with the literature, pedagogy, and research methods are necessary for such a course to provide teachers with the full spectrum of skills and knowledge. Such a mind-set is consistent with the ideas promoted by targeted conferences on preparing $\mathrm{K}-12$ teachers [27] and the recommendations of the American Institute of Physics. [28].

The work we describe here addresses only the most basic elements of instruction on KSI, namely, content knowledge as learned during instruction in a one-semester course. It would, of course, be useful to follow future teachers from this course into their teaching positions and study how and to what extent they apply their KSI or other PCK in their teaching. Similarly, one could focus on the conceptual and 
TABLE I. Course I instructional units.

\begin{tabular}{|c|c|c|}
\hline Physics content & Curriculum emphasized & Research method studied \\
\hline Electric circuits & $\begin{array}{l}\text { Tutorials in Introductory Physics [12] and } \\
\text { materials from Gutwill et al. [31] }\end{array}$ & $\begin{array}{l}\text { Analysis of free-response pretest and posttest } \\
\text { responses }[32,33]\end{array}$ \\
\hline Kinematics & $\begin{array}{l}\text { Activity-Based Tutorials [13,14], Real Time } \\
\text { Physics [11], and Powerful Ideas in } \\
\text { Physical Science [10] }\end{array}$ & $\begin{array}{l}\text { Free-response questions, multiple-choice surveys } \\
\text { [Test of Understanding Graphs-Kinematics } \\
\text { (TUG-K)] [34] and Force and Motion } \\
\text { Conceptual Evaluation (FMCE) [35] }\end{array}$ \\
\hline $\begin{array}{l}\text { Forces and Newton's } \\
\text { laws }\end{array}$ & $\begin{array}{l}\text { Tutorials in Introductory Physics [12] and } \\
\text { UMaryland Open Source Tutorials (as } \\
\text { described in Ref. [36]) }\end{array}$ & $\begin{array}{l}\text { Multiple-choice surveys [Force Concept } \\
\text { Inventory (FCI) [37] and FMCE [35]] }\end{array}$ \\
\hline
\end{tabular}

epistemological development of the students of our program's graduates. We hope that the research described here forms the basis for such future studies.

\section{CONTEXT FOR RESEARCH}

Our PER courses exist under several constraints due to the population targeted for the MST program. This population includes in-service physics teachers, either in or out of field; professional scientists or engineers transitioning into careers in education; physics graduate students, most (but not all) of whom are doing PER for their Ph.D.; and MST students from other science and mathematics fields. As a result of this variety, the class spans a wide range of knowledge of both physics and pedagogical content. Many students enrolled in the course were concentrating in mathematics, chemistry, or biology, so took the course as an elective; others were moving into physics teaching from another field (e.g., math, chemistry, biology, etc.).

A great deal of the literature and curricular materials that we cover in the course are based on the generalizations that have been made regarding the results in physics education research, especially as is related to the improvement of students' conceptual understanding [29,30]. Our goal, as stated previously, is to have the future teachers recognize, through reading and discussion of the literature, experiencing the curricular materials, and learning to use the basic research methods of PER, the importance of reflection on and discussion about physics content and student knowledge thereof, in order to gain a more coherent understanding of both the content and how best to teach it. Additionally, students encounter general issues of learning and teaching in science and mathematics primarily drawing on the literature in educational psychology and the learning sciences. However, that is beyond the scope of the course described in this paper and is addressed in a different course that is required of all MST students.

It should be mentioned that the course(s) described here have far more modest goals than the full graduate program described by Etkina [26]. There are only two disciplinespecific courses for each discipline in the MST program, as well as an educational psychology course and various seminar courses. Given the span of the preparation of our candidates, the fact that these courses are not taken exclusively by future physics teachers, and our emphasis on including a research component, our courses are necessarily broader in scope and thus unavoidably less thorough at accomplishing the many goals of a full graduate program specifically designed for physics teachers.

To show the coherence of instructional materials, research methods, and research literature, we split our PER courses into content-based units. Instructional units for one course are presented in Table I, and those for the other in Table II.

TABLE II. Course II instructional units.

\begin{tabular}{|c|c|c|}
\hline Physics content & Curriculum emphasized & Research method studied \\
\hline $\begin{array}{l}\text { Mechanical wave pulses, sound; } \\
\text { mathematics of exponential functions }\end{array}$ & Activity-Based Tutorials $[13,14]$ & $\begin{array}{l}\text { Analysis of interview data }[38,39] \text {; comparing } \\
\text { multiple-choice to free-response questions [40] }\end{array}$ \\
\hline $\begin{array}{l}\text { Work-energy and impulse-momentum } \\
\text { theorems }\end{array}$ & Tutorials in Introductory Physics [12] & $\begin{array}{l}\text { Individual student interviews [41]; assessment } \\
\text { question formats: free-response, multiple- } \\
\text { choice, multiple-choice-multiple-response [42] }\end{array}$ \\
\hline Various, primarily kinematics & $\begin{array}{l}\text { Excerpts from Ranking Tasks [43], } \\
\text { Tasks Inspired by Physics Education } \\
\text { Research [44] }\end{array}$ & $\begin{array}{l}\text { Various forms of assessment-formative or } \\
\text { summative }\end{array}$ \\
\hline Thermodynamics & $\begin{array}{l}\text { UC Berkeley laboratory-tutorials } \\
\text { [45], Physics by Inquiry [8] }\end{array}$ & $\begin{array}{l}\text { Classroom interactions; curriculum develop- } \\
\text { ment and modification }\end{array}$ \\
\hline
\end{tabular}


The first course contains the most studied topics in the PER literature for which effective instructional materials exist, as demonstrated in the research literature: electric circuits (dc), kinematics, and dynamics. We use these areas to demonstrate various research methodologies, including the analysis of pretests and posttests, and the development of broad assessment tools and survey instruments. We use electric circuits before mechanics because our experience, and that of others, is that thinking about electric circuits qualitatively is often difficult for people regardless of their physics backgrounds, and so starting with circuits would put the different student populations in the class on a more equal footing at the outset.

The second course contains topics with less literature on learning and teaching at the college and high school level: mechanical waves and sound, the work-energy and impulse-momentum theorems, and basic thermodynamics. We use these topics to expose the class to more qualitative research methods, including interviews, design of different kinds of assessments and the difference in student responses between those assessments, classroom interactions, and guided-inquiry curriculum development and modification.

A typical cycle of instruction lets future teachers experience the use of several common teaching and research tools: (1) pretests on the physics that will be studied, to explore the depth of understanding of our future teachers (many are weak in physics, and we need to know how best to help them); (2) pretests on what introductory students might believe about this physics, to see how good a picture the future teachers have of student reasoning about the topic; (3) instruction on the physics using published, research-based curricula, as listed above; (4) discussion of the research literature on the physics topic, typically based on papers directly related to the instructional materials, but often set up to complement and create discussion; (5) homework dealing primarily with the physics, and sometimes also the pedagogy; and (6) posttests on all three areas of physics, pedagogy, and research and how they intersect.

Students practice clinical interview skills, and as part of an in-class research project, design a short set of instructional materials to use. There is no formal practical teaching component in our course such as microteaching. ${ }^{1}$

\footnotetext{
${ }^{1}$ MST students seeking certification carry out student teaching at the secondary level, and are observed and scored using an observation protocol partly based on the Reform Teaching Observation Protocol [46,47]. Many of our students are also teaching assistants in reform (and traditional) courses at the university level. They are also observed and scored with the protocol, after which the observers and the student discuss the observed "lesson."
}

\section{ASSESSMENT OF FUTURE TEACHER PEDAGOGICAL CONTENT KNOWLEDGE IN THE COURSE}

Our assessments match our course goals. We probe conceptual understanding of content by asking questions from, or based on, the research-based and -validated curricular materials used in class. To assess the grasp of the research findings and methodologies, we ask for comparative analysis of literature, or of analysis of data in light of discussions in specific papers. We assess understanding of pedagogy and curricular effectiveness by asking for comparisons between different research-based instructional strategies, and comparative analysis of different curricular materials to address a specific difficulty. Finally, we assess the development of an understanding of student ideas by asking the future teachers themselves to generate hypothetical student responses to questions unfamiliar to the future teachers.

We present one example from the context of electric circuits. Before instruction, the future teachers answer the "five-bulbs" question [32] and also predict what an "ideal incorrect student" might answer in a similar situation (Fig. 1). ${ }^{2}$ A reasonable incorrect response on the five-bulbs analysis task would match results from the research literature and be self-consistent throughout the response, although students are often inconsistent when giving incorrect answers. As part of the unit lesson, the future teachers analyze typical responses by categorizing 20 anonymous student responses before reading the research results $[32,33]$ on this question. One class period is spent on discussions of different categorizations. Next, the future teachers work through research-based instructional materials that begin with simple series and parallel circuits and progress through $R C$ circuits. Students consider several curricula that they might use for teaching their own future students about current (see Table I) and discuss the merits and weaknesses of each. Finally, they are tested on their understanding of the physics and the research literature on student learning and possible instruction choices. To show understanding, they must refer to the correct physics and the literature as appropriate.

Tests typically have in-class and take-home components to allow for the evaluation of more time-consuming analyses of student thinking. The in-class component is demonstrated in Fig. 2. The take-home component (see Appendix) typically includes analysis of data that are new to the future teachers-it could be an interview excerpt, a set of student free responses, or a series of multiple-choice responses from a group of students-that

\footnotetext{
${ }^{2}$ We should point out that while the circuits unit focuses on incorrect student ideas, and on interpreting incorrect student responses to identify specific difficulties-which is how the literature addresses the issue-in a later unit on forces and motion we include curricular materials that are designed to build on student intuitions about the content [33].
} 
1. The three circuits below contain identical bulbs and identical batteries. Assume the batteries are ideal.

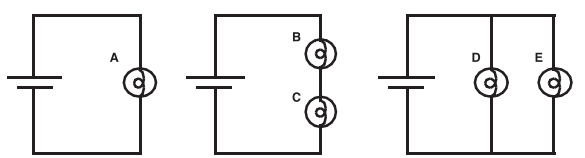

Rank the brightnesses of the five bulbs above, from greatest to least. Explain how you determined your answer.

2. Consider a student giving an incorrect response to question 1 . Give this "student's" response in the space below and explain which pieces of the student's reasoning are incorrect. Assume that the rankings and models are consistent (i.e. that the student is "ideal"). If your answer does not sufficiently explain the ranking, include the additional assumptions that the "student" might be making in giving this response.

FIG. 1. "Five-bulbs" question (1) [32] and extension to assess knowledge of student ideas (KSI) (2). Correct response (for ideal batteries and bulbs): $\mathrm{A}=\mathrm{D}=\mathrm{E}>\mathrm{B}=\mathrm{C}$. Common incorrect responses (meaning, "correct KSI responses") include $\mathrm{A}>\mathrm{B}=$ $\mathrm{D}=\mathrm{E}>\mathrm{C}$ for current-used-up explanations and $\mathrm{A}>\mathrm{B}=\mathrm{C}=$ $\mathrm{D}=\mathrm{E}$ for fixed-current, current-sharing models.

is then analyzed so they can respond to specific questions or issues, and discuss the data in light of the literature covered in the class. In sum, we test whether our students learn the correct physics concepts and whether they can predict, analyze, and classify incorrect responses they are likely to encounter when teaching, to better understand their students' thinking about the content. In later parts of the course we also ask students to suggest, design, or critique instructional materials that address typical incorrect responses.

Our emphasis on having future teachers discuss student reasoning in homework assignments in our class has increased since the creation of our courses. In the first few years, we explicitly avoided asking about student ideas on the homework, focusing instead on the future teachers' understanding of the relevant physics. More recently we have added some questions that include KSI into the homework, to allow future teachers the opportunity to practice what they have learned in our class. KSI questions were included on the exams in the course. Our instruction was therefore better aligned with our assessment.

Having described the course format and sources of data on future teacher reasoning about student learning and understanding, we now discuss the data we have gathered and how we analyze it. We provide data on student understanding of concepts through responses to seminal questions and conceptual surveys from the PER literature. As stated previously, data on future teacher KSI understanding come from responses to questions on the same physics concepts assessed by the content questions. After asking future teachers to provide responses to content questions, we then ask them to provide example(s) of incorrect student responses to these same questions. Figure 1 shows an

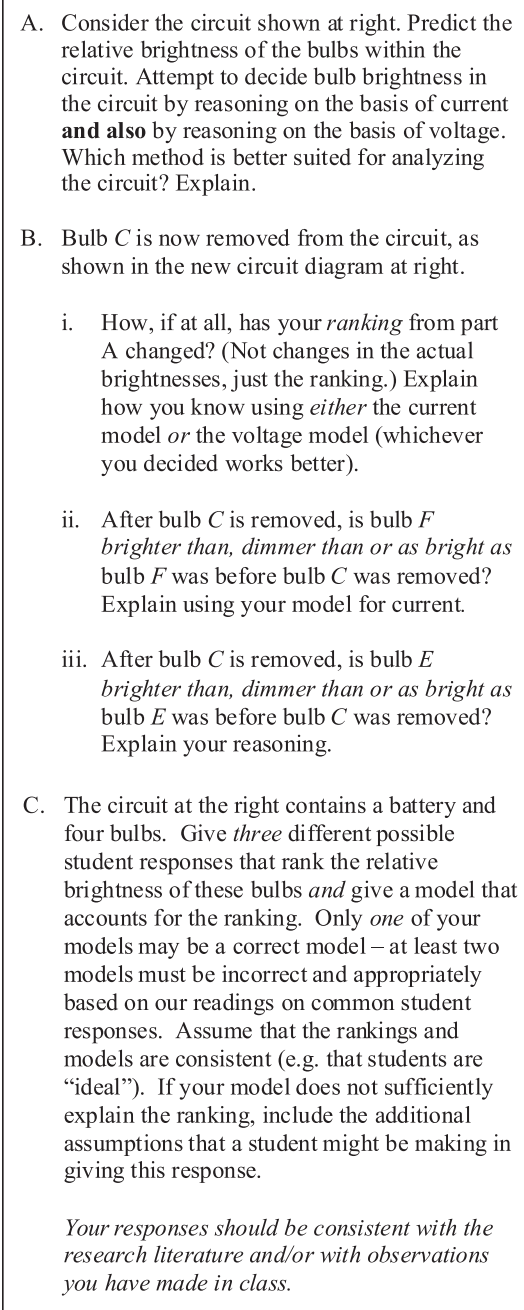

A. Consider the circuit shown at right. Predict the relative brightness of the bulbs within the circuit. Attempt to decide bulb brightness in the circuit by reasoning on the basis of current and also by reasoning on the basis of voltage. Which method is better suited for analyzing the circuit? Explain.

B. Bulb $C$ is now removed from the circuit, as shown in the new circuit diagram at right.

i. How, if at all, has your ranking from part A changed? (Not changes in the actual brightnesses, just the ranking.) Explain how you know using either the current model $o r$ the voltage model (whichever you decided works better).

ii. After bulb $C$ is removed, is bulb $F$ brighter than, dimmer than or as bright as bulb $F$ was before bulb $C$ was removed? Explain using your model for current.

iii. After bulb $C$ is removed, is bulb $E$ brighter than, dimmer than or as bright as bulb $E$ was before bulb $C$ was removed? Explain your reasoning.

C. The circuit at the right contains a battery and four bulbs. Give three different possible student responses that rank the relative brightness of these bulbs and give a model that accounts for the ranking. Only one of your models may be a correct model - at least two models must be incorrect and appropriately based on our readings on common student responses. Assume that the rankings and models are consistent (e.g. that students are "ideal"). If your model does not sufficiently explain the ranking, include the additional assumptions that a student might be making in giving this response.

Your responses should be consistent with the research literature and/or with observations you have made in class.

FIG. 2. Posttest questions for content (A), (B) and KSI (C) for electric circuits. (A) is based on a homework question in Physics by Inquiry [8]; (C) is based on unpublished posttest data. The instructions in italics at the bottom were not included until the third time the course was taught. [Correct KSI responses to question (C) are shown in Figs. 6 and 7.]

example of the paired questions we asked before instruction on electric circuits. After instruction, the questions are more focused: the content questions are more difficult, and the KSI question has the added requirement of consistency with literature or evidence. The pretest question (which was used every semester) was the five-bulbs set shown in Fig. 1; while different posttests were used for different semesters, features of these questions were similar. One version of a post-test question is shown in Fig. 2.

The results obtained are analyzed for several factors. We sought correct content understanding. We also judged responses on the extent to which the future teachers demonstrated knowledge of incorrect student models as documented in the literature. Some future teachers were quite specific about the way a student would be thinking to justify a particular response, while others gave reasoning 
that was less rigorous, but still reasonable. This led to a third level of analysis to account for any errors or vagueness in the KSI responses, that is, the consistency of those responses with the PER literature. We now proceed to discuss this phase of the analysis.

During the first few years of the course, the posttests contained no explicit mention of tying any incorrect responses to the PER literature. Unfortunately, this led to some responses that could be considered reasonable incorrect solutions, but had not been identified in the literature as either a single common conceptual difficulty or a combination of difficulties (i.e., a seemingly plausible incorrect answer that is unlikely to be encountered by the future teacher in a classroom of students). Eventually we added the instructions seen in italics at the bottom of Fig. 2 to individual questions; more recently we have put a more general pronouncement on the exam paper about the need for consistency with research literature. These changes have helped us receive answers more aligned with our assessment goals, though the low numbers of students in a given course preclude us from a meaningful analysis of how student responses have changed over time.

Tables III and IV show preliminary results for electric circuits. Before instruction, the future teachers themselves displayed an array of incorrect responses consistent with the published literature on electric circuits $[32,33]$ on the content portion of the pretest (see Fig. 3). After instruction, students performed very well despite substantially more difficult questions.

In our analysis of the future teacher responses in content and in KSI, we were specifically looking for those "conceptual difficulties" that are documented in the research literature. Therefore "correct" or "nearly correct" answers were defined by the omission of any incorrect conceptual thinking. For example, on the content question, if there was one minor error (for example, one reversal in the ranking and/or reasoning of a six- or seven-bulb circuit, analogous to, say, the dropping of a factor of 2 in a long numerical solution) — rather than evidence of a more serious and pervasive specific difficulty-it implied a procedural error rather than a deep-seated one, and we classified that response as being "nearly correct" in that area. We similarly classified a future teacher response as "nearly correct" on KSI if their generated student response(s) were consistent with literature but lacked explicit descriptions of

TABLE III. Correct responses on content: Performance comparison of graduate students in displaying appropriate content knowledge on electric circuits as a result of instruction in the graduate course. (See Fig. 1 for before instruction and Fig. 2 for after instruction questions.)

\begin{tabular}{lc}
\hline \hline & $N=26$ (matched sample) \\
\hline Before instruction & $58 \%$ \\
After instruction & $85 \%$ \\
\hline \hline
\end{tabular}

TABLE IV. Appropriate KSI. Performance comparison of graduate students in displaying appropriate KSI on electric circuits as a result of instruction in the graduate course. (See Fig. 1 for before instruction and Fig. 2 for after instruction questions.)

\begin{tabular}{lc}
\hline \hline & $N=26$ (matched sample) \\
\hline Before instruction & $54 \%$ \\
After instruction & $96 \%$ \\
\hline \hline
\end{tabular}

student reasoning or student models, e.g., the ranking of bulbs was consistent with a well-documented incorrect student idea but the model was not articulated precisely, or their reasoning was a bit perfunctory. Examples of correct and nearly correct responses are shown in Figs. 4 and 5, respectively.

In the KSI analysis, before instruction most students were unfamiliar with the published research material on common student ideas about circuits, and therefore most of their examples about common incorrect student thinking were described from a more intuitive point of view. In Fig. 4, a response given on a pretest is shown; the future teacher described brightness due to "electricity," but also went on to carefully describe the ranking for each bulb. By contrast, the ranking shown in Fig. 5 is inconsistent with the accompanying explanation, which focuses on power rather than current or voltage. However, in general the response is consistent with common student reasoning, so it was classified as nearly correct.

Postinstruction testing covered several questions. We felt the need to make a distinction between some of the

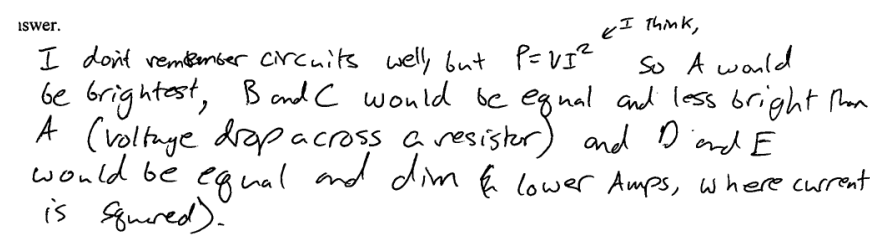

FIG. 3. Incorrect future teacher pretest response to five-bulbs question (Fig. 1). In this response the future teacher uses voltage reasoning correctly for ranking bulbs $\mathrm{A}, \mathrm{B}$, and $\mathrm{C}$; their ranking and reasoning for $\mathrm{D}$ and $\mathrm{E}$ suggests the idea that the battery acts as a constant current source, consistent with results seen in the literature $[13,14]$.
$\mathrm{A}>\mathrm{B}=\mathrm{D}>\mathrm{C}=\mathrm{E}$

$A$ is the brightest because all the electricity goes to it. B \& D are the next brightest because they' re closest to the battery in their respective circuits. C \& E are dim since $B \& D$ use up some electricity before it gets to $C \& E$.

FIG. 4. Future teacher response modeling student response to five-bulbs question, before instruction. This response was classified as "correct" with respect to PCK. 


\section{$A<B \circ C<D<E$}

\section{A hur the noct pores, BrC have half the pover, int D hus mave parar then E, Sul less then A.}

FIG. 5. Future teacher response modeling student response to five-bulbs question, before instruction. This was classified as "nearly correct" for PCK.

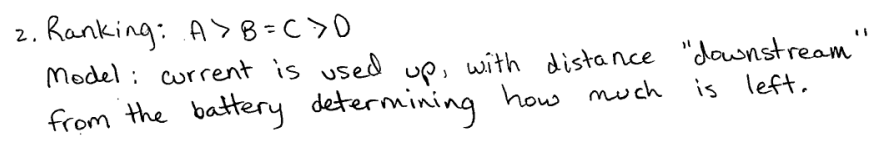

FIG. 6. Future teacher response modeling student response to posttest question (C) in Fig. 2. This was classified as correct for PCK.

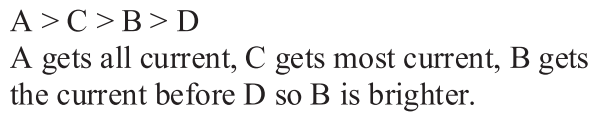

FIG. 7. Future teacher response modeling student response to posttest question (C) in Fig. 2. This was classified as "nearly correct" for PCK.

student responses that were reasonable but primarily intuitive as opposed to those that seemed to be informed by the literature. As mentioned previously, it may seem initially to be desirable for a future teacher to think up a novel and viable incorrect student response, but it is not pedagogically useful if a student is extremely unlikely to come up with such a response.

The circuit used in part $\mathrm{C}$ on the posttest question shown in Fig. 2 was deliberately chosen because it has been administered in introductory courses after tutorial instruction, and while the question itself has been presented in a peer-reviewed conference proceedings [48], the responses have been analyzed but not published other than in a doctoral dissertation [49]. This circuit leads to an interesting pedagogical situation: it is possible to obtain the correct ranking of the bulbs using incorrect reasoning that couples two different conceptual difficulties. A student who uses the incorrect idea that current splits in half at any junction (documented in [32]) and the incorrect idea that bulbs in series "share" or split current evenly (documented in [49]) would provide the correct ranking $(\mathrm{A}>\mathrm{C}>\mathrm{B}=\mathrm{D})$; approximately $10 \%$ of students in the study in Ref. [49] provide reasoning suggesting ideas related to sharing of current in series. This question thus provides the opportunity for future teachers to anticipate this response based on their reading of the literature combined with their own insight.

The response in Fig. 6 includes a brief but precise description of student thinking, in this case "current is used up"; this response was scored correct for PCK. In the nearly correct posttest response shown in Fig. 7, the ranking and explanation are given, but the future teacher fails to describe which incorrect student model is being described, and therefore this looks more like a pretest description, where the incorrect student explanations are determined from intuition rather than the research literature. So while the answers in both cases would be scored correct for course evaluation purposes, the attention to informed knowledge of student ideas, rather than what appear to be a more intuitive ideas, is reflected in the difference in our assessment scores.

Figure 8 shows results of future teacher knowledge on both content knowledge [Fig. 8(a)] and knowledge of student ideas [Fig. 8(b)] for the electric circuits questions shown in Figs. 1 and 2. For the data presented in this paper, the course enrolled twice as many students with a physics background $(N=16)$ as those with a nonphysics background $(N=8)$. Analysis of performance by physics background shows one distinct feature and the potential for
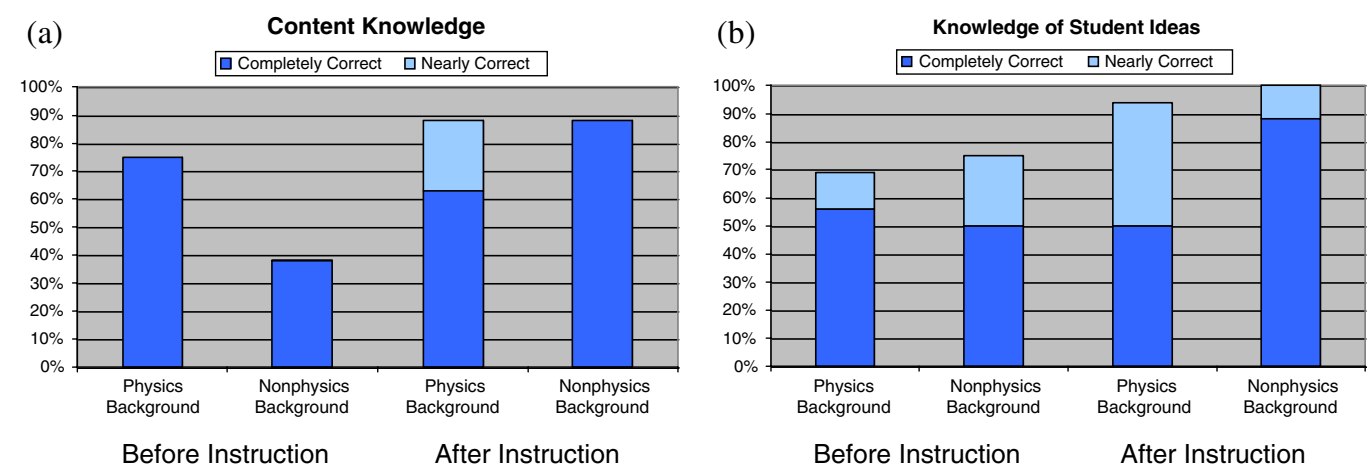

FIG. 8 (color online). Preinstruction and postinstruction results for multiple semesters of the class $\left(N=24 ; N_{\text {physics }}=16\right.$; $N_{\text {nonphysics }}=8$ ) on (a) content knowledge and (b) pedagogical content knowledge for the electric circuits unit. "Nearly correct" responses are those that contain one minor error over several questions (CK) or explanations that were somewhat vague (PCK), but still technically correct. 
another. First - and unsurprisingly — future teachers with a nonphysics background performed far worse on content knowledge questions before instruction than those with a physics background. The second is plausible but inconclusive at this point due to an insufficient sample size. It would seem that a higher proportion of students with a nonphysics background were coded as completely correct for KSI than were students with a physics background ( $p<0.13$ using a test of binomial proportions).

\section{DISCUSSION OF PRELIMINARY RESEARCH FINDINGS}

Although our investigation is still in its initial phase and thus our findings are tentative, we discuss several possible implications of our analysis. The results presented above suggest a hypothesis that may be borne out with further study: a larger proportion of future teachers with a nonphysics background provide model student responses consistent with documented student difficulties in electric circuits than do those with a physics background. This result coincides with the finding that both groups end up with similar overall performance on content knowledge.

These findings are somewhat surprising-one expects stronger content knowledge to lead to better KSI. We offer a few interpretations of these findings. One possibility is that the nonphysics future teachers are being more careful in crafting their responses on the posttests than the physics future teachers, since the content is somewhat unfamiliar to them. In that light, this result suggests a need to vary assessment strategies in order to obtain multiple readings of KSI and content knowledge. A second interpretation is that the future teachers without a background in physics are more aware of incorrect or naive student ideas about the content, since they themselves may have harbored similar ideas at the beginning of the course. This is consistent with pretest responses we see from future teachers who have no physics background, in which they tell us to consider their own response to the content question as a model incorrect student response. These types of responses are absent in the pretest responses of the future teachers with a background in physics and the posttest responses from either group.

\section{CONCLUSION}

We have designed a course that uses the literature and products of physics education research to deepen future teachers' content knowledge while also developing their abilities to recognize and understand the common student ideas that exist in the classroom. Our course contains features of a discipline-based PCK-oriented course, as suggested by van Driel et al., and our efforts to assess the effectiveness of the course to improve PCK advances the agenda of increasing the research base on the role of discipline-specific PCK in teacher preparation put forth by these researchers $[19,20]$. Our focus within the very broad area of PCK on knowledge of student ideas is common to many PCK frameworks in science education. This focus is also a central component of the framework described by Ball and collaborators in mathematics education research [23,24]. Magnusson et al. [21] point out that addressing common student ideas, even when teachers know that they exist, is not trivial. Having future teachers work through curricular materials that contain instructional strategies explicitly designed to target specific student difficulties can provide touchstone examples from which teachers can build, thus strengthening that aspect of their pedagogical content knowledge.

We have developed a methodology for investigating future teachers' content knowledge and knowledge of student ideas using a variety of assessments, both before and after instruction. We have analyzed performance on our assessments while paying special attention to differences in physics and nonphysics backgrounds among our future teachers. We find from our preliminary analysis that our course provides future teachers with tools to anticipate student thinking, to incorporate student ideas about the content into their teaching and assessment, and to analyze student responses from various types of assessments. While we acknowledge that our sample size at this time is still small, we argue that these findings nevertheless demonstrate the utility of the methodology that we are advocating. These findings are consistent with aspects of pedagogical content knowledge espoused by many different researchers in science and mathematics education, but they are not explicitly taught or assessed in most science and mathematics education research or physics teacher preparation programs. Our course design and commensurate research begin to address the need for the PER community to engage in helping future teachers develop both content knowledge and knowledge of student ideas, an essential part of pedagogical content knowledge.

We are interested in furthering this investigation with the continued collection of data which we hope will enable us to make more definitive claims about the evolution of student content understanding throughout this course and how that may or may not impact future teachers' PCK. As we focus on this narrow thread of PCK-knowledge of student ideas-we recognize that we do not make any attempt to map out the ways future teachers might use these ideas in the classroom, which is likely to be one of the most crucial aspects of this type of work. Nor have we tapped into how a teacher's development of PCK might affect their epistemological development as they encounter alternative ways of thinking and learning that might affect their view of their role in the classroom. We acknowledge these shortcomings of our work; however, as Etkina points out, there are limits to what can be done in the preparation years of a teacher's career, and an individual's PCK may need to develop over the course of many years [26]. We suggest that if we can successfully develop a methodology 
that proves fruitful even in a few small areas, it may give researchers some tools to use in other investigations.

\section{ACKNOWLEDGMENTS}

We gratefully acknowledge support for the course development and the research from the Maine Academic
Prominence Initiative, the Maine Economic Improvement Fund, and NSF Grant No. DUE-0962805.

\section{APPENDIX: TAKE-HOME EXAM}

See separate auxiliary material for a sample of the takehome component of the exam.
[1] R. Duit, Bibliography-STCSE: Students' and Teachers' Conceptions and Science Education, http://www.ipn .uni-kiel.de/aktuell/stcse/stcse.html [most recent (and final) version March 2009; last accessed May 6, 2011].

[2] J. R. Thompson and B.S. Ambrose, A Literary Canon in Physics Education Research, APS Forum on Education Fall 2005 Newsletter, 16, 2005. Also available at http:// units.aps.org/units/fed/newsletters/fall2005/canon.html.

[3] C.E. Wieman and K.K. Perkins, Transforming physics education, Phys. Today 58, No. 11, 36 (2005).

[4] M. Wittmann and J. Thompson, Integrated approaches in physics education: A graduate-level course in physics, pedagogy, and education research, Am. J. Phys. 76, 677 (2008).

[5] L. C. McDermott, Millikan Lecture 1990: What we teach and what is learned-Closing the gap, Am. J. Phys. 59, 301 (1991).

[6] L. Shulman, Those who understand: Knowledge growth in teaching, Educ. Researcher 15, 4 (1986).

[7] L. C. McDermott and E. F. Redish. Resource letter PER-1: Physics education research, Am. J. Phys. 67, 755 (1999).

[8] L. C. McDermott, Physics by Inquiry (Wiley, New York, 1996).

[9] P. W. Laws, Workshop Physics (Wiley, New York 1996).

[10] Powerful Ideas in Physical Science, http://aapt.org/ Publications/pips.cfm.

[11] D. R. Sokoloff, R. K. Thornton, and P. W. Laws, Real Time Physics (Wiley, New York, 1998).

[12] L. C. McDermott, P. S. Shaffer, and The Physics Education Group at the University of Washington, Tutorials in Introductory Physics (Prentice-Hall, Upper Saddle River, NJ, 2002).

[13] M.C. Wittmann, R. N. Steinberg, and E.F. Redish, Activity-Based Tutorials: Introductory Physics (Wiley, New York, 2004), Vol. 1.

[14] M.C. Wittmann, R. N. Steinberg, and E.F. Redish, Activity-Based Tutorials: Modern Physics (Wiley, New York, 2005), Vol. 2.

[15] F. Goldberg, S. Robinson, and V. Otero, Physics for Elementary Teachers (It's About Time, Armonk, NY, 2006).

[16] F. Goldberg, S. Robinson, R. Kruse, N. Thompson, and V. Otero, Physical Science and Everyday Thinking (It's About Time, Armonk, NY, in press).

[17] N. S. Podolefsky and N. D. Finkelstein. Use of analogy in learning physics: The role of representations, Phys. Rev. ST Phys. Educ. Res. 2, 020101 (2006).
[18] N. S. Podolefsky and N. D. Finkelstein, Analogical scaffolding and the learning of abstract ideas in physics: An example from electromagnetic waves, Phys. Rev. ST Phys. Educ. Res. 3, 010109 (2007).

[19] J.H. van Driel, N. Verloop, and W. de Vos, Developing science teachers' pedagogical content knowledge, J. Res. Sci. Teach. 35, 673 (1998).

[20] J. Loughran, P. Mulhall, and A. Berry, In search of pedagogical content knowledge in science: Developing ways of anticipating and documenting professional practice, J. Res. Sci. Teach. 41, 370 (2004).

[21] S. Magnusson, J. Krajcik, and H. Borko, in Examining Pedagogical Content Knowledge: The Construct and Its Implications for Science Education, edited by J. GessNewsome and N.G. Lederman (Kluwer Academic, Dordrecht, 1999), pp. 95-132.

[22] R. Goertzen, R. Scherr, and A. Elby, Tutorial TAs in the classroom: Similar teaching behaviors are supported by varied beliefs about teaching and learning, Phys. Rev. ST Phys. Educ. Res. 6, 010105 (2010).

[23] H. Hill, D. Ball, and S. Schilling, Unpacking pedagogical content knowledge: Conceptualizing and measuring teachers' topic-specific knowledge of students, J. Res. Math. Educ. 39, 372 (2008).

[24] D. L. Ball, M. H. Thames, and G. Phelps, Content knowledge for teaching: What makes it special?, J. Teach. Educ. 59, 389 (2008).

[25] E. Etkina, Physics teacher preparation: Dreams and reality, J. Phys. Teach. Educ. Online 3, 2 (2005).

[26] E. Etkina, Pedagogical content knowledge and preparation of high school physics teachers, Phys. Rev. ST Phys. Educ. Res. 6, 020110 (2010).

[27] G. A. Buck, J. G. Hehn, and D. L. Leslie-Pelecky, The Role of Physics Departments in Preparing K-12 Teachers (American Institute of Physics, College Park, MD, 2000).

[28] AIP-Member Society Statement on the Education of Future Teachers, http://www.aps.org/policy/statements/ 99_1.cfm.

[29] L. C. McDermott, Oersted Medal Lecture 2001: "Physics Education Research-The Key to Student Learning”, Am. J. Phys. 69, 1127 (2001).

[30] E.F. Redish, Teaching Physics with the Physics Suite (Wiley, NY, 2003).

[31] J.P. Gutwill, J. R. Frederiksen, and B. Y. White, Making their own connections: Students' understanding of multiple models in basic electricity, Cogn. Instr. 17, 249 (1999). 
[32] L. C. McDermott and P. S. Shaffer, Research as a guide for curriculum development: An example from introductory electricity. Part I: Investigation of student understanding, Am. J. Phys. 60, 994 (1992).

[33] L. C. McDermott and P. S. Shaffer, Research as a guide for curriculum development: An example from introductory electricity. Part II: Design of an instructional strategy, Am. J. Phys. 60, 1003 (1992).

[34] R. J. Beichner, Testing student interpretation of kinematics graphs, Am. J. Phys. 62, 750 (1994).

[35] R. K. Thornton and D. R. Sokoloff, Assessing student learning of Newton's laws: The force and motion conceptual evaluation and the evaluation of active learning laboratory and lecture curricula, Am. J. Phys. 66, 338 (1998).

[36] R. E. Scherr and A. Elby, Enabling informed adaptation: Open-source physics worksheets integrated with implementation resources, in Proceedings of the 2006 Physics Education Research Conference, edited by P. Heron, L. McCullough, and J. Marx, AIP Conf. Proc. No. 883 (AIP, New York, 2007), pp. 46-49.

[37] D. Hestenes, M. Wells, and G. Swackhamer, Force concept inventory, Phys. Teach. 30, 141 (1992).

[38] M.C. Wittmann, R.N. Steinberg, and E.F. Redish, Understanding and affecting student reasoning about the physics of sound, Int. J. Sci. Educ. 25, 991 (2003).

[39] K. V. P. Menchen and J. R. Thompson, Student understanding of sound propagation: Research and curriculum development, in Proceedings of the 2004 Physics Education Research Conference, edited by J. Marx, P. Heron, and S. Franklin, AIP Conf. Proc. No. 790 (AIP, New York, 2005), pp. 81-84.

[40] M.C. Wittmann, R.N. Steinberg, and E.F. Redish, Making sense of students making sense of mechanical waves, Phys. Teach. 37, 15 (1999).
[41] R. A. Lawson and L. C. McDermott, Student understanding of the work-energy and impulse-momentum theorems, Am. J. Phys. 55, 811 (1987).

[42] T. O'Brien Pride, S. Vokos, and L.C. McDermott, The challenge of matching learning assessments to teaching goals: An example from the work-energy and impulse-momentum theorems, Am. J. Phys. 66, 147 (1998).

[43] T.L. O'Kuma, D.P. Maloney, and C. J. Hieggelke, Ranking Task Exercises in Physics (Addison-Wesley, Reading, MA, 2004).

[44] C. J. Hieggelke, D. P. Maloney, T. L. O'Kuma, and S. Kanim, E\&M TIPERs: Electricity \& Magnetism Tasks (Addison-Wesley, Reading, MA, 2006).

[45] N. M. Gillespie, Knowing thermodynamics: A study of students' collective argumentation in an undergraduate physics course, Ph.D. thesis, University of California, Berkeley, 2004.

[46] D. Sawada, M. Piburn, E. Judson, J. Turley, K. Falconer, R. Benford, and I. Bloom, Measuring reform practices in science and mathematics classrooms: The Reformed Teaching Observation Protocol, School Sci. Math. 102, 245 (2002).

[47] D.L. MacIsaac and K.A. Falconer, Reforming physics education via RTOP, Phys. Teach. 40, 479 (2002).

[48] S. Kanim, Connecting concepts about current to quantitative circuit problems, in Proceedings of the 2001 Physics Education Research Conference, edited by S. Franklin, J. Marx, and K. Cummings (Rochester, NY, 2001), pp. 139-142.

[49] S.E. Kanim, An investigation of student difficulties in qualitative and quantitative problem solving: Examples from electric circuits and electrostatics, Ph.D. thesis, University of Washington, 1999. 